\title{
Learning Support for Standard e-Classroom
}

\author{
Gabriel ZAMFIR \\ Department of Economic Informatics and Cybernetics, \\ The Bucharest University of Economic Studies, Romania, \\ gabriel.zamfir@ie.ase.ro
}

\begin{abstract}
Normative approaches developed in the traditional education system are based on the classical resources, and this type of formal education reveals more and more restrictions, both for teaching and for evaluations, as soon as information has still an exponential development. At the same time, the informal education recognised as the regional information systems and the non-formal education reflected as the global information system evolve as a learning environment with more and more consequences for students. In this context, the formal education requires to be reorganized as a national information system according to the functionalities of the e-society, consolidated on the main three building blocks: e-Education, e-Science and $e$-Business. This article is designed as a conceptual one, focused on specific features of the eclassroom, considered as the standard technological infrastructure, defined as an extension of the traditional classroom in e-education. The purpose of this analysis is to highlight the new paradigm of meta-instruction in e-education as it is profiling as the basement of the learning support in standard e-classroom.
\end{abstract}

Keywords: Assisted Instruction, Educational Research, E-Articles, Assisted Individual Study, Qualifications and Occupational Standards

1 Introduction

Information has still an exponential development since the appropriate technology had been devised and information technology had become a scientific research field. In education, information technology has to move the boundary between teaching and learning in the same manner in which the technological infrastructure harmonizes theory and practice in science or the suppliers and the customers in business.

Such an approach has to focus to the central concept of the e-society, which is qualification, and this fact explains why e-education is valuable both as an end in itself, and as an engine of the community. The development of the conceptual approaches for describing qualifications is currently an important priority for any country.

In $[1$, p.22] is specified that traditional models and methods of expressing qualifications structures are giving way to systems based on explicit reference points using learning outcomes and competencies, levels and level indicators, subject benchmarks and qualification descriptors. These devices provide more precision and accuracy and facilitate trans- parency and comparison. Without these common approaches, full recognition, real transparency and thus the creation of an effective European Higher Education Area, will be more difficult to achieve. In a similar vision, [2, p.3] mention that in The European Qualifications Framework for lifelong learning $(\mathrm{EQF})$, a learning outcome is defined as a statement of what a learner knows, understands and is able to do on completion of a learning process. The EQF therefore emphasises the results of learning rather than focusing on inputs such as length of study. Learning outcomes are specified in three categories - as knowledge, skills and competence. This signals that qualifications - in different combinations - capture a broad scope of learning outcomes, including theoretical knowledge, practical and technical skills, and social competences where the ability to work with others will be crucial.

In the section Some Terminology Issues Concerning Key Competencies, [3, p. 291-292] mention that notions such as competence, competency, skill, ability, know-how, capacity, capability and aptitude are used or associated with different meanings according to the 
context and are sometimes considered more or less equivalent. Moreover, in many countries, it is difficult to make a clear distinction between skills and competences or competencies. The same author highlights that even the official European terminology maintains some ambiguity. For example, on the IATE (Interactive Terminology in Europe) website 'competence' is translate into French as 'compétence', but 'skill' is also translated as 'compétence', which reflects the real world, since skills and competences in French are often used indiscriminately in the general education sphere.

In this context, in Romania, it was built the National Higher Education Registry (http://www.rncis.ro/), which it offers options for advanced search selecting fundamental domain, science branch, hierarchy domain, and study program and it displays a related summary, including professional competences, transversal competences, and possible occupations for the owner of the diploma. In the latest regulations it is mentioned a deadline for the higher education institutions, in order to update this national registry. At the same time, there is the National Qualifications Authority, where, at present time, there are published 853 occupational standards (http://www.anc.edu.ro/?page_id=42); the methodology assigned to these results is available. (ARACIS) which is an autonomous public institution, of national interest, whose main mission is the external evaluation of the Romanian higher education's quality, at the level of study programmes, as well as from the institutional point of view. ARACIS uses an online platform for registering and evaluation of experts included in $\mathrm{Na}-$ tional Register of Evaluators (http://www.aracis.ro/nc/en/aracis/).

As a special approach, it has to highlight that transversal competences are defined in the first annex of the National Education Law no $1 / 2011$. The transversal competences represent valuable and attitudinal acquisitions which cross over a domain or study program and they are reflected through the next descriptions: autonomy and responsibility, social interactions, personal and professional development.

A working definition of transversal competencies is presented in [4, p.4-5]. In this report it is declared that there are significant variations in the definition and interpretation of transversal competencies among participating countries and economies. So, each country and economy would clarify and use their own definitions of transversal competencies under each domain in their studies. As a conclusion, each domain would remain generic, and they are presented in Table 1.

Table 1. UNESCO's Working Definition of Transversal Competencies

\begin{tabular}{|l|l|}
\hline Domains & Examples of Key Characteristics \\
\hline Critical and innovative thinking & $\begin{array}{l}\text { Creativity, entrepreneurship, resourcefulness, application } \\
\text { skills, reflective thinking, reasoned decision-making }\end{array}$ \\
\hline Inter-personal skills & $\begin{array}{l}\text { Presentation and communication skills, leadership, or- } \\
\text { ganizational skills, teamwork, collaboration, initiative, } \\
\text { sociability, collegiality }\end{array}$ \\
\hline Intra-personal skills & $\begin{array}{l}\text { Self-discipline, enthusiasm, perseverance, self- } \\
\text { motivation, compassion, integrity, commitment }\end{array}$ \\
\hline Global citizenship & $\begin{array}{l}\text { Awareness, tolerance, openness, respect for diversity, in- } \\
\text { tercultural understanding, ability to resolve conflicts, civ- } \\
\text { ic/political participation, conflict resolution, respect for } \\
\text { the environment }\end{array}$ \\
\hline $\begin{array}{l}\text { Optional domain: (Example) } \\
\text { Physical and psychological health }\end{array}$ & $\begin{array}{l}\text { Healthy lifestyle, healthy feeding, physical fitness, empa- } \\
\text { thy, self-respect }\end{array}$ \\
\hline
\end{tabular}

According to previous approaches concerning scientific research in e-society [5], theory and practice are two conceptual interdependent components, structured in a desktop- 
fieldwork paradigm, reflecting the metalanguage and the object language. In the same manner, e-education and e-business are two conceptual interdependent components based on e-science. Synthetizing, we could conclude that e-society is based on three pillars which depend on qualifications, as it is presented in Figure 1.
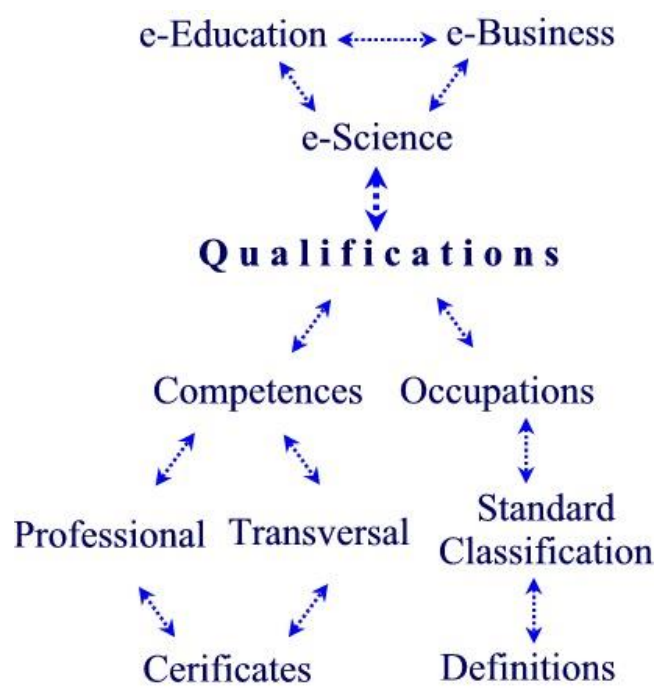

Fig. 1. Conceptual paradigm of the e-society

One important issue in this approach is to highlight, as it is presented in [6], that transversal competences are recognized as the teachers' important skills in their organization of the teaching and learning process and their professional development, as well as in the process of them teaching these competences to their students. The same author is mentioning that teachers are the result of their "cumulative autobiography", so they act on the basis of his/her constructs, beliefs and understanding of human learning, professional growth and development. This fact is considered in our analyse being an unrevealed side of the meta-instruction related to an individual, investigated as a central component of the cognitive infrastructure in an eeducation system.

\section{Knowledge Framework}

As soon as the interrelationship between the building blocks of an e-education system is defined as a threefold infrastructure consisting of technological, cognitive and conceptual, next step is about the dynamics of each part. So, another important issue of this study is to observe that over the time, first there were developing facts, and second these were getting labels, while, in recent times, there are a lot of labels already created, while the corresponding facts are late or just only in progress. Referring to e-science's input, resources come primary from e-education features, secondly from e-business structures, while e-science's output are focused on ebusiness applications then the implementations occur in e-education, reflecting an inherited behaviour.

Continuing the previous research, as they are shown in [5] and [7], the e-article could be defined as the basic result of a scientific research activity in e-science. At the same time, production of the e-articles is bigger and bigger and some of these are using for learning, as knowledge objects more or less refined, for understand and apply, and some of these become objects for analyse, synthesise and evaluation. The two situations could be reflected as a study trying to find in virtual world the very first scientist or understanding scientometrics; these are two examples in order to present diversity in scientific research, as soon as the word 'scientist' entered the English language in 1834 and there is an interesting history in order to define it, while bibliometrics become webometrics and then Scientometrics 2.0 based on Social Network Data and it is going to include new ontologies. On the other hand, using a search engine or a meta-search engine with the keywords timeline in education, we find out that the blackboard was invented in 1801 by James Pillans. In 1990, as an improvement, whiteboards begin to erase the chalkboard from schools (after they have been promoted in business). In 1960, the overhead projector allowed instructors to use reusable printed transparencies (but first in the army communities). In 1999, early versions of interactive boards were wired to desktop computers, while the latest models can connect with mobile devices.

We remembered the search-engines, so we have to remember the semantic search- 
engines, as a kind of applications that will change the world of search.

A useful investigation in order to understand our dynamic environment could be found in [8], where e-society is assumed from three versions, i.e. E-version for electronic, Dversion for digital and $\mathrm{V}$-version for virtual. All three can be used as prefix. The three versions are interrelated to each other and reflect progresses not only in technologies and but also in applications for our activities. After a terminological analyse of these versions, it has been found that some terms in the categories of these versions are interchangeable, some are not. In general, E as a prefix can be placed before terminology of subjects and objects alike, whereas the D and V suit technology alike. As a first conclusion, any traditional resource could become an electronic resource; for example, a book becomes an ebook, when its functionalities are reduced to sequential or indexed-sequential access, and the book became a digital book when its functionalities are diversified. A traditional museum could become a virtual museum. It is interesting to observe that a tradition library could begin to offer digital library services, then it could be transformed in a digital library, finally becoming a virtual library, and the main differences are marked by the diversity of the library functionalities. A traditional classroom becomes e-classroom as soon as the teacher is present; the student follows an e-class when he is at home, and the e-class becomes a virtual class when the technologies are diversified.

Such a judgement could explain an adequate comprehension for numerous prefixes associated with learning, term which reflects, by default, a typical human activity. In this context, [9] describes e-learning as the way people use an electronic device (usually a computer) with learning technology to develop new knowledge and skill individually or collaborative; mobile devices with learning technologies constitute various forms of wireless environments can have many functions to promote mobile learning (mlearning); the same author highlights that since the early 2000s new forms of mobile technology containing additional sensor devices have been providing new directions for technology-assisted learning, and this has led to context-aware ubiquitous learning (ulearning). Based on the same evolution of technology-enhanced learning, [10] and [11] complete the stages with a new one, called Smart Learning sustained by social technologies. It has to be present that previous researches, such as [12], consider necessary a redefinition of the term social technology, as soon as the concept of social technologies has several aspects which destabilize the dominant status of technology.

Another strategy for learning in e-education is b-learning (blended learning) which is analysed in [13], considering that e-learning has become widely used in every type of education (traditional and formal education, continuous education and corporate training) because of its characteristics such as flexibility, richness of materials, resource-sharing and cost-effectiveness. In this work, the author paid more attention to the blended-learning (b-learning) systems, which consider systems "combining face-to-face instruction with computer-mediated instruction". B-learning has been largely used in the context of higher education, and it includes a wide range of learning formats such as self-study and instructor-led in both an asynchronous and synchronous mode. [14] analyse e-learning as a concept, and associate e-Learning 1.0, 2.0 and 3.0 with the prevalent technologies available in their kin Web versions (1.0, 2.0 and 3.0 respectively). In a survey of predictions, they highlight that e-Learning concept of "anytime, anywhere and anybody" will be complemented by "anyhow", i.e. it should be accessible on all types of devices (alearning).

Based on the three paradigms of the learning in e-society presented in [5] as the lexical one, the terminological one and the conceptual one, and according to the interrelationships between the building blocks of an eeducation system developed in [15], a conceptual framework for a functioning esociety is shown in Figure 2. 


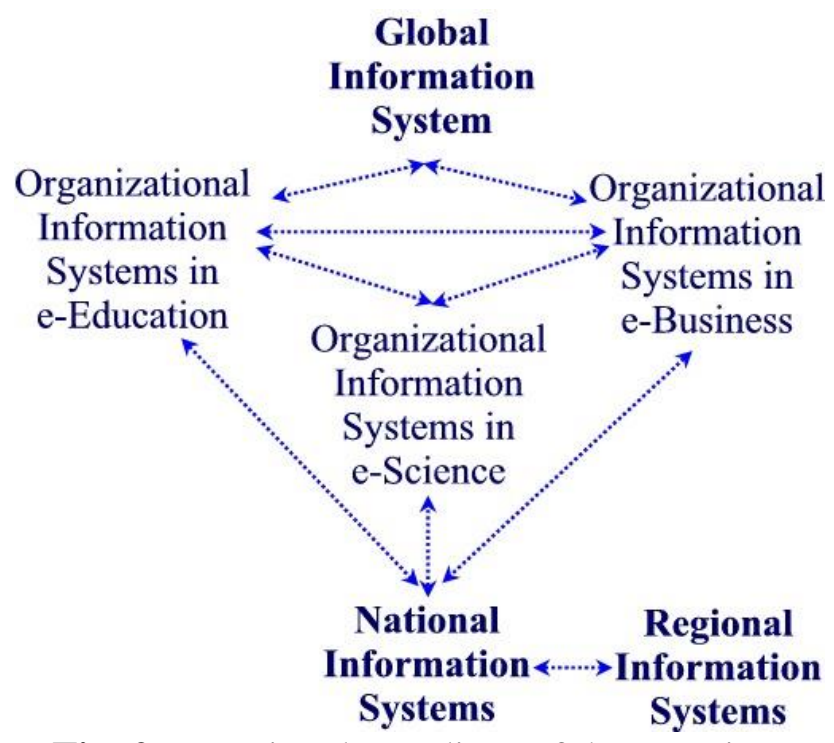

Fig. 2. Functional paradigm of the e-society

This approach highlights the three forms of the traditional education system: the formal, the informal and the non-formal education reflected as web components for a learning perspective in e-society and consists of the building blocks for a knowledge framework oriented to comprehension.

\section{Comprehension Framework}

A study involved in educational research [16], it creates a paradox when considers that what knowledge is, and the ways of discovering it, are subjective, as soon as it concludes that it is important for English language teachers to understand the underlying ontological and epistemological assumptions behind each piece of research that they read. The author continues mentioning that teachers need to be able to recognize how these assumptions relate to the researcher's chosen methodology and methods, and how these assumptions connect to the findings which are presented in journal articles. First remark is that English is the native language for the information technology domain and second, in this domain, initially it is determinant and then relevant, to analyse the term knowledge distinctively, in meta-language or in objectlanguage. The working language of the educational research has to imply the term knowledge connected with data and information, as soon as the interrelations could form different ontologies for research. There are textbooks in which the authors distinguish between data, information, and knowledge. In [17], as the author mentions, the term "data" refers to the syntax, "information" refers to the interpretation, and "knowledge" refers to the way information is used.

Using a search-engine, i.e. Google, looking for information, we find, for example, 8.890.000.000 results in 0,50 seconds. First results are definitions for information offered by different dictionaries; next pages could be structures in different domains (.edu, .com, .org, .gov, .net) or in different virtual entities, such as journals, libraries or other educational institutions, research centres, national institutes located in different geographic places. For the same search, Yahoo! Offers $3,140,000,000$ results, beginning with some dictionaries and continuing with specific addresses, such as: information.com, www.information.dk, information.tv, www.informationr.net and so on. Similar and combined results could be obtained when using meta-search engines, such as Dogpile, Infospace, Mamma or WebCrawler. Ixquick offers about 3,799,999,551 results and it is mentioned that Ixquick does NOT record the user IP address! First is published a personalized ads related to the keyword. When looking for knowledge, the same application of- 
fers about 33,099,095 results, ads related to the keyword and a tip about customize Ixquick. The options refer to search language, interface language, date search, servers and search engines. Yippy, looking for information, offers top 470 results of at least $3,830,000,000$ retrieved for the query. Yippy Dictionary (from WordNet) lists 1. information, info - (a message received and understood); 2. Data, information - (a collection of facts from which conclusions may be drawn; "statistical data"); 3. Information (knowledge acquired through study or experience or instruction); 4. information, selective information, entropy - ((communication theory) a numerical measure of the uncertainty of an outcome; "the signal contained thousands of bits of information"); 5 information - (formal accusation of a crime). Yippy, looking for knowledge, offers top 602 results of at least 35,800,000 retrieved for the query. Yippy Dictionary (from WordNet) lists 1. cognition, knowledge, noesis - (the psychological results of perception and learning and reasoning). Yippy, looking for data, offers top 406 results of at least 673,000,000 retrieved for the query. Yippy Dictionary (from WordNet) lists 1. data, information - (a collection of facts from which conclusions may be drawn; "statistical data"); 2. datum, data point - (an item of factual information derived from measurement of research).

Using a semantic search-engine, WolframAlpha in order to look for the keyword information

(https://www.wolframalpha.com/input/?i=inf ormation), we find that first known use of information in English was in the Late Middle ages, in 1387, and we get five definitions for this word: a) a message received and understood, b) knowledge acquired through study or experience or instruction, c) formal accusation of a crime, d) a collection of facts from which conclusions may be drawn and e) (communication theory) a numerical measure of the uncertainty of an outcome. Using the same semantic search-engine, looking for knowledge

(https://www.wolframalpha.com/input/?i=kn owledge), we find a word frequency history from 1539 to 2007, in occurrences per hundred thousand words per year and we get a definition: the psychological result of perception and learning and reasoning. We find two synonyms, cognition and noesis, and a list with 34 narrower terms, each of them included as a hyperlink. Using the same semantic search-engine, WolframAlpha), when looking for the keyword data, (https://www.wolframalpha.com/input/?i=dat a) the application structures different perspectives to continue: assuming "data" refers to a formula, use as a general topic, or a physical quantity, or a financial entity, or a word or referring to sound input or a species specification instead. As a word, data is defined as a noun, being collected information typically used for reference or analysis. First known use in English: 1646 (European Renaissance).

In an assisted instruction system, based on a standard technological infrastructure, i.e. an e-classroom, where functionality is provided by teacher assisted learning, data is a lexical component of a vocabulary which implies knowing syntax. Information is a terminological component of a discipline which requires understanding semantics. Knowledge is a conceptual component of a domain which involves applying pragmatics. Data, as a term could become information as well as information, as a concept, could become knowledge.

This flow is a twofold routing assigned to the cognitive infrastructure of the participants, in order to harmonise the conceptual infrastructure of the content: the teacher offers the appropriate data, or information or knowledge for the zone of proximal development of the learner; the teacher has to identify and solve the troublesome knowledge generated by the threshold concepts or by missing concepts in the learner's cognitive infrastructure [18]. This harmonisation is based on the two components of the meta-instruction: previous activities of the teacher in the field of eeducation and previous activities of the learner for understanding. For any content could be used e-articles as learning support, and the teacher could develop his own script 
of e-articles in order to sustain a progressive process for knowing, understanding and applying the appropriate data, or information or knowledge.

In this context, based on the knowledge framework presented in [15], scientific research could be defined as a paradigm between theory and practice, related to the cognitive infrastructure of the researcher. As soon as scientific research supposes two languages, theory includes ontology as an object language and epistemology as the metalanguages, while practice contains methods as an object language and methodology as the meta-languages. Such an approach confers a paradigm of assisted instruction in eeducation, as it is shown in Figure 3.

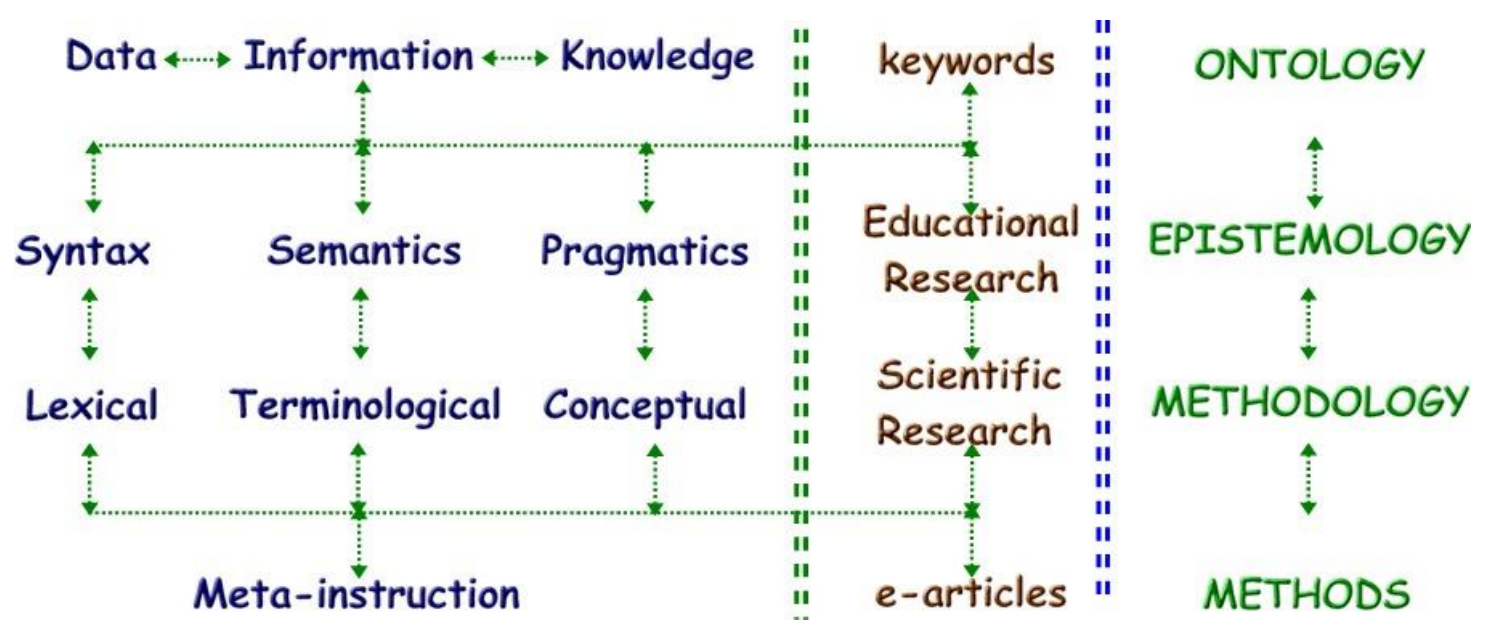

Fig. 3. The interrelationships between the building blocks of assisted instruction in eeducation

Each notion of this paradigm is developed as a construct in a meta-language for a metadiscipline, in order to integrate an interdisciplinary approach.

\section{Application Framework}

In order to design an assisted instruction environment in the e-classroom, based on the analytical framework presented in [18], consisting of the concepts map approach, the context for developing explicit knowledge, and the pattern of a didactical developing of the content, in Figure 4 is presented a para- digm which integrates the traditional class, as course and seminar, in a laboratory activity; this is based on the principles of an assisted instruction system: individualized learning, personalized learning, interactivity founded on the triple-vision of the personal computer as tool, tutor and tutee, the adequate information granularity of the content, assisted instruction developed as a meta-discipline while it integrates inter-disciplinary approaches because of the diversity as forms of knowing, and trans-disciplinary approaches because of diversity as forms of knowledge.

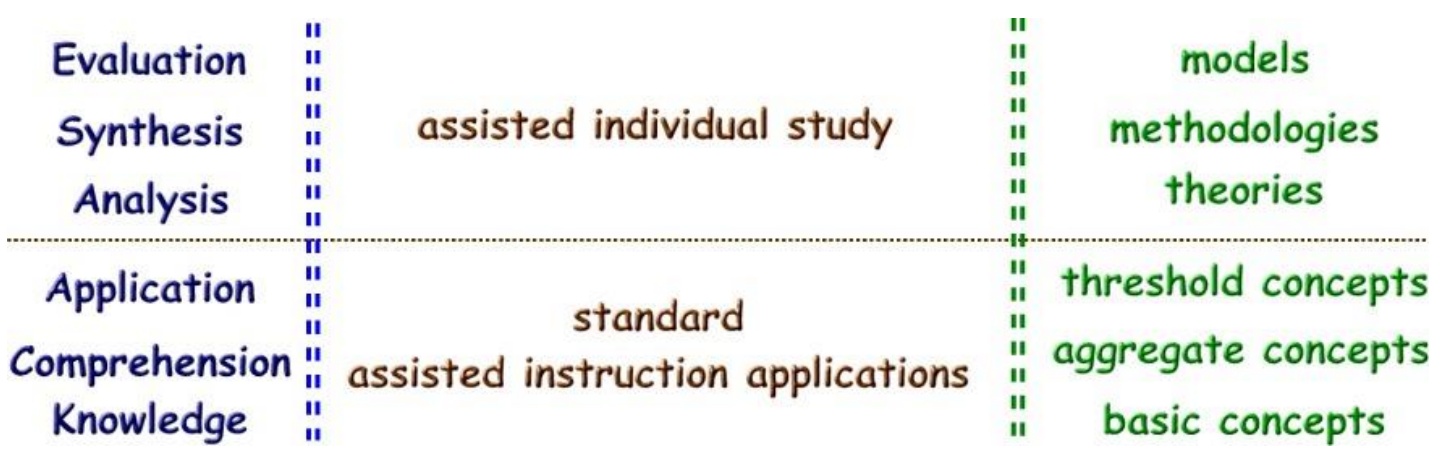

Fig. 4. The paradigm of meta-instruction related to Bloom's taxonomy and concepts map 
Continuing the analyse presented in [19], where for a learning process the content is developed using a concepts map integrated as a pyramid of notions enabled for knowing, understanding and applying, while the teaching process is designed on a concepts map aggregated in a network of notions enabled to analyse, systematize and evaluate the content of the subject, we find two levels for this approach: a practical one, based on standard assisted instruction applications, and a theoretical one, centred on assisted individual study, see Figure 4. In a pyramid there are concepts as basis or aggregate, while in a network, the concepts could be considered, functionally, as threshold concepts. In assisted instruction, the applications design for learning include a sequential set of tasks, gradually developed from simple to complex and focused on knowing, understanding and applying notions used in theories, methodologies and models. It is the role of the assisted individual study, in a face-to-face interaction in the eclassroom as teacher assisted learning, to harmonise the conceptual infrastructure of the content in the zone of proximal development of the learner and to identify and solve the troublesome knowledge generated by the threshold concepts or by missing concepts in his cognitive infrastructure.

The assisted individual study could be developed based on e-articles, and treated as a dedicated environment for learning with all the e-learning functionalities understood as support, as soon as the e-article represents the basic result of a scientific research activity in e-science.

\section{Case Study}

One of the conclusions argued in [19] mentioned that an e-educational scientific research program's output should become an environment of instruction for a student's study program. This idea could be explained by the conceptual paradigm of learning in esociety developed in [5], where e-education is a consequence of e-science.

Society becomes e-society through levels of technology; the great principle of resolving traditional problems with the new technology could be translate as a first level of applications, and for learning that it means that each traditional resource could be transformed in an electronic resource; and this is the Eversion for electronic as we understand the dynamic of e-society. The second level is based on using efficiently the new resources, so the solutions are appropriate to new environment; this is the D-version for digital as we understand an irreversible e-society.

The student's study program's objectives consist of professional and transversal competencies and they are developed through discipline's classwork. Beginning with Comenius, the discipline's classwork is based on the school-book. Over time, the schoolbooks developed as we refer to content or to format, depending on educators and technologies. We can go back in the past (for example, visiting https://archive.org/details/cu3192403249945 5 to read The Orbis Pictus of John Amos Comenius, as an electronic-book, or for short, e-book) or we can explore the strategy of the Romanian Ministry of Education and Scientific Research, visiting http://www.manuale.edu.ro/ in order to read the digital version or the printable version of the school-books for the first and for the second degree. Both examples demonstrate us that the personal computers are, by default, the actual learning support in e-education. In e-education, the personal computer could be treated as a tool, or as a tutor, or at a higher level, as a tutee. A standard assisted instruction application integrates all these types of support, and it became an educational context, learning oriented.

In e-Classroom, the discipline theorized emerges in the discipline practiced and both converge in a new discipline. This new discipline has to educate both the students and the teachers, in a laboratory activity.

Designing interactive applications for training the students involves the two languages of an e-educational scientific research: the meta-language and the object language.

In the following example, we develop an interactive application for assisted instruction where the user is the student and his compre- 
hension is based on teacher assisted learning, and the language consists of adequate terminology in context, alternatively from the meta-language and from the object language. The student could question any moment for any clarification during the assisted individual study, as soon as his activity is based on a personalized e-article.

Let's consider the next assisted individual study, as the first activity of the assisted instruction laboratory in the third year of a Bologna first cycle; its title is: E-Society - the Paradigm of Assisted Instruction.

Keywords: teacher assisted learning, qualifications and occupational standards, national information systems, word processor - assisted instruction environment, Bachelor's Degree

Assisted instruction is developed as a discipline which it has as the main goal learning optimising. Learning, defined as knowledge acquisition process or as knowledge through instruction process, is conditioned by the environment where it is happened or it is organized. The same like the scientific research activity, learning presumes a descriptive language for the content of the studied field, but at the same time, it is essential to use an explaining language, necessary to understand and apply according to that content. Developing the domain of information technology as a scientific research programme generated the conditions for creating a technological infrastructure associated to that programme. In e-education, the educational infrastructure promoted concepts like software program and application, meta-language and object language, assisted design for educational support and personalized educational support when we describe or understand learning as a human activity, learning becoming a conversion between the default knowledge and explicit knowledge.

The European Higher Education Area (EHEA) was launched along with the Bologna Process' decade anniversary, in March 2010, during the Budapest-Vienna Ministerial Conference. As the main objective of the Bologna Process since its inception in 1999, the EHEA was meant to ensure more compa- rable, compatible and coherent systems of higher education in Europe. The next decade will be aimed at consolidating the EHEA and thus the current EHEA permanent website will play a key role in this process of intense internal and external communication (http://www.ehea.info/). This permanent website includes an electronic bulletin board for events, an electronic archive, an electronic glossary and a lot of other electronic resources in this domain. In this context, learning outcomes are defined as statements of what a learner is expected to know, understand and/or be able to do at the end of a period of learning, and qualification for higher education means any degree, diploma or other certificate issued by a competent authority attesting that particular learning outcomes have been achieved, normally following the successful completion of a recognised higher education programme of study. Here is defined the National framework of qualifications for higher education, as being the single description, at national level of level of an educational system, which is internationally understood.

In Romania, it was developed a national information system, the National Higher Education Registry (http://www.rncis.ro/) which offers the connections between the higher education institutions and the qualifications, including professional and transversal competences, and the related occupational standards.

There are different kind of searches and different criteria, according to the structures and hierarchy domains, so the students are able to know and to understand their position and professional perspectives. In the image presented in Figure 5 there is an example of an advanced search in the National Higher Education Registry, for the fundamental domain social science, and in the science branch economics, for the study domain Economic Cybernetics, Statistics and Informatics. The result of this search consists of three summaries, corresponding to the three study programs available in the hierarchy domain.

Each summary includes all the criteria selected in the search and details the profes- 
sional competences, transversal competences the faculties which offer the study program, and there are also available possible occupations, included or not included yet in the Classification of Occupations in Romania.

The occupational standards are elaborated by the National Qualifications Authority, and they are available at http://www.anc.edu.ro/?page_id=42.

The Romanian Agency for Quality Assurance in Higher Education (ARACIS) was established in 2005 and is an autonomous pub- lic institution, of national interest, whose main mission is the external evaluation of the Romanian higher education's quality, at the level of study programmes, as well as from the institutional point of view. ARACIS is a full member of the European Association for Quality Assurance in Higher Education ENQA and is registered in the European Quality Assurance Register for Higher Education - EQAR. See for further information http://www.aracis.ro/nc/en/aracis/.

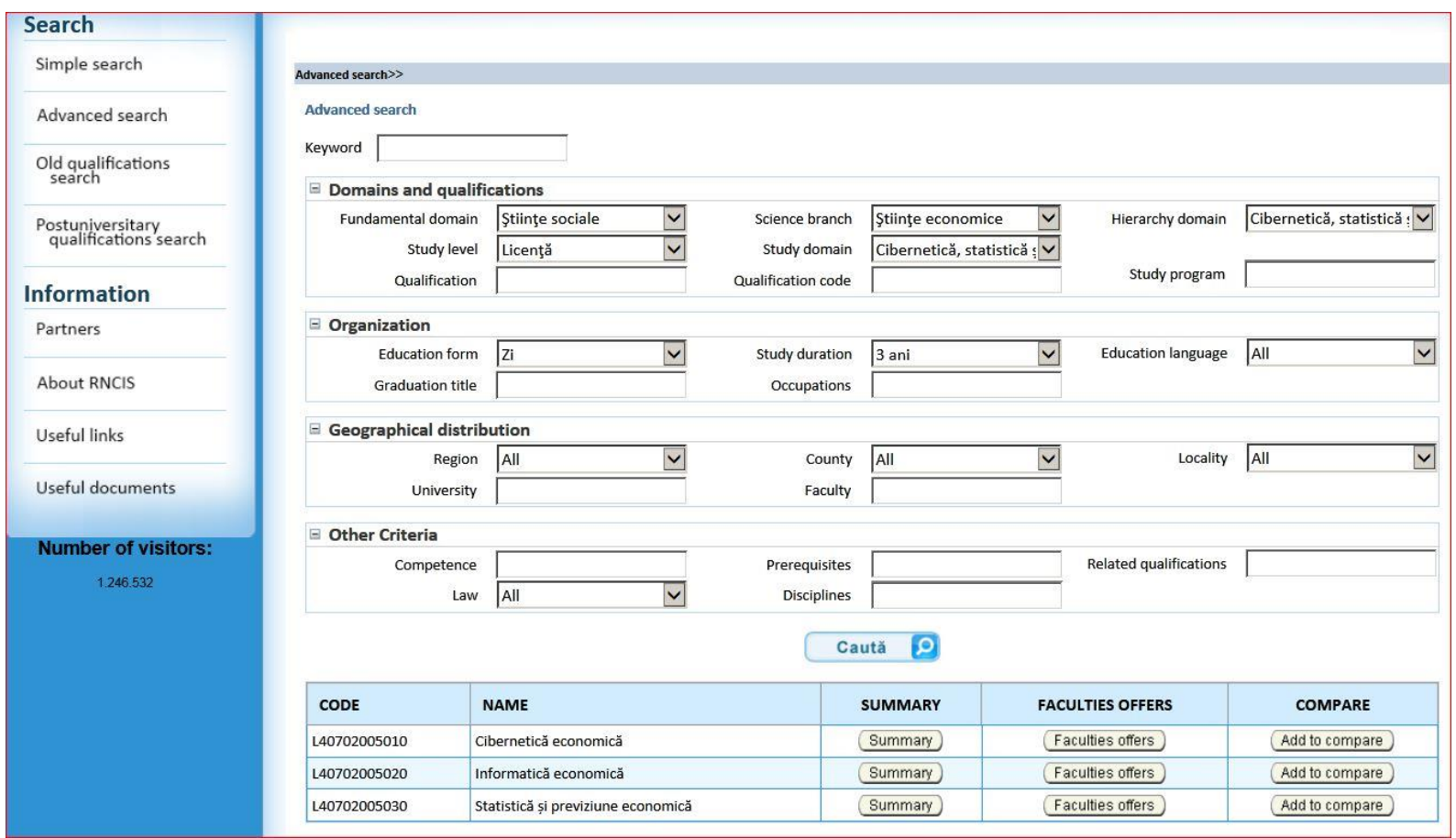

Fig. 5. Advanced search in National Higher Education Registry

In order to clarify any concept according to the terminology of the content, you may access the electronic-glossary available at http://www.iac.ase.ro/glosar/.

In order to find an example of the features of learning in e-society, based on the relationship between e-science and e-education, please open the e-article Learning Paradigms in e-Society, available at http://www.revistaie.ase.ro/content/67/09\%2 0-\%20Zamfir.pdf, as an electronic article, for short e-article. In the section Conceptual Framework there are described the main features of learning in e-society, while in the section Analytical Framework there are mentioned the main options of the word proces- sors, as a dedicated environment for developing e-articles, scientific research papers, school-books, or even the final papers for Bachelor's degree. You can find quickly the content described above, looking for word processor.

In order to complete this assisted individual study, please send a message at the email address of the discipline, with the subject your

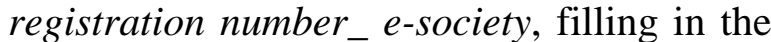
blanks in this form:

1. After visiting the National Higher Education Registry and after an advanced search regarding your hierarchy domain, please mention:

a) Your study program; 
b) The most important professional competence for you, and give a reason;

c) The most important transversal competence for you, and give a reason;

d) A possible occupation you are looking for;

e) Which is the new occupation you consider more attractive?

2. Give an example of another national information system you already visited, and mention why do you consider it a national information system?

3. After reading the section about word processor options, mention which of them do you consider they are mandatory for your final Bachelor's paper? Please, synthesize seven of them;

4. Mention specific e-society resources you already used during this assisted individual study.

This type of learning support produced for developing the course and the seminar into a laboratory activity, illustrated here as an assisted individual study generate four kind of new interactions between the student and the teacher: during the study for any possible explanations required by the student, because of the final questions, as a result of the evaluation of the answers, and as a future content and format, designed for a new study, based on the teacher's observations and conclusions.

\section{Conclusions}

This paper developed as a theoretical study in educational scientific research describes an approach in order to highlight specific activities in e-classroom designed for a personalized instruction in e-education; based on the main principles of the teacher assisted learning system, developed in a standard eclassroom in e-education, this approach is advanced in order to integrate the learning environment of the e-classroom in eeducation through e-science; e-education could be developed as an informatics application of e-Science in e-Society, and these principles have to be integrated in standard assisted instruction applications, supporting the design of specific didactic activities. At the same time, this approach highlights the idea that learning is design as a recursive process in training both the teachers and the students. In e-Classroom, the classwork involves the object language and the metalanguage as two variables which integrate the fieldwork in the deskwork, as an environment for the basis specific competences. In eClassroom the discipline theorized emerges in the discipline practiced and both converge in a meta-instruction assisted learning system.

\section{References}

[1] *** - A Framework for Qualifications of the European Higher Education Area, Bologna Working Group on Qualifications Frameworks, Published by: Ministry of Science, Technology and Innovation, Copenhagen K, 2005, pg. 200, ISBN (internet): 87-91469-53-8; see also http://www.iac.ase.ro/support/

[2] $* * *$ - The European Qualifications Framework for Lifelong Learning (EQF), Luxembourg: Office for Official Publications of the European Communities, 2008, ISBN 978-92-79-08474-4, DOI $10.2766 / 14352$, pg. 16 , see also http://www.iac.ase.ro/support/

[3] G. Halász \& A. Michel - Key Competences in Europe: interpretation, policy formulation and implementation, European Journal of Education, Vol. 46, No. 3, 2011, p. 290-306, Blackwell Publishing Ltd.

[4] *** - Transversal Competencies in Education Policy \& Practice, Phase I, Regional Synthesis Report, Published in 2015 by the United Nations Educational, Scientific and Cultural Organization 7, place de Fontenoy, 75352 Paris 07 SP, France and UNESCO Bangkok Office, (C) UNESCO 2015, pg. 80 ISBN: 978-929223-509-3 (Electronic version) This publication is available in Open Access under the Attribution-ShareAlike 3.0 IGO (CC-BY-SA $3.0 \quad$ IGO) license (http://creativecommons.org/licenses/by$\mathrm{sa} / 3.0 / \mathrm{igo} /)$. By using the content of this publication, the users accept to be bound by the terms of use of the UNESCO 
Open Access Repository

(http://www.unesco.org/open-

access/terms-use-ccbysa-en)

[5] G. Zamfir - Learning Paradigms in eSociety,Informatica Economică, Volume 17, No. 3/2013, INFOREC Publishing House,

DOI:

10.12948/issn14531305/17.3.2013.09,

ISSN 1453-1305, EISSN 1842-8088,

Available

online:

http://revistaie.ase.ro/content/67/09\%20-

\%20Zamfir.pdf

[6] R. Čepić, S. Tatalović Vorkapić, D. Lončarić, D. Anđić \& S. Skočić Mihić Considering Transversal Competences, Personality and Reputation in the Context of the Teachers' Professional Development, International Education Studies; Vol. 8, No. 2; 2015, ISSN 1913-9020 EISSN 1913-9039, Published by Canadian Center of Science and Education (http://www.ccsenet.org/journal/index.ph $\mathrm{p} / \mathrm{ies}$ )

[7] G. ZAMFIR - Quality-Quantity Paradigm in Assisted Instruction, Journal of Applied Quantitative Methods, vol. 5, No. 4, Winter 2010, ISSN: 1842-4562, http://www.jaqm.ro

[8] X. Zhang , H. Lundin - Understanding ESociety by E, D and V, published in the volume of the Proceedings of the IADIS International Conference on e-Society, Ávila, Spain 16-19 July 2004, Edited by Pedro Isaías, Maggie McPherson, Piet Kommers, ISBN (Book): 972-98947-5-2

[9] Gi-Zen Liu and Gwo-Jen Hwang - A key step to understanding paradigm shifts in e-learning: towards context-aware ubiquitous learning, published in British Journal of Educational Technology, Volume 41 No 2 2010, doi:10.1111/j.14678535.2009.00976.x

[10] E. K Adu and D. C C Poo - Smart Learning: A New Paradigm of Learning in the Smart Age, paper presented at TLHE 2014, International Conference on Teaching \& Learning in Higher Education, National University of Singapore, http://www.cdtl.nus.edu.sg/tlhe/tlhe2014/ abstracts/aduek.pdf
[11] Gwo-Jen Hwang - Definition, framework and research issues of smart learning environments - a context-aware ubiquitous learning perspective, Smart Learning Environments 2014, 1:4, http://www.slejournal.com/content/1/1/4

[12] A. Skaržauskienè, R. Tamošiūnaitè and Inga Žalènienè - Defining Social Technologies: evaluation of social collaboration tools and technologies, The Electronic Journal Information Systems Evaluation Volume 16 Issue 3 2013, (232-241), available online at www.ejise.com

[13] P. Peres, L. Lima and V. Lima - BLearning Quality: Dimensions, Criteria and Pedagogical Approach, European Journal of Open, Distance and eLearning, Vol. 17 / No. 1 - 2014, ISSN 1027-5207, DOI: 10.2478/eurodl-20140004

[14] N. Rubens, D. Kaplan, and T. Okamoto - E-Learning 3.0: anyone, anywhere, anytime, and AI, International Workshop on Social and Personal Computing for WebSupported, SPeL 2011, http://activeintelligence.org/wpcontent/papercite-data/pdf/elearning-30rubens-spel-2011--preprint.pdf

[15] G. Zamfir - Assisted Learning Systems in e-Education, Informatica Economică, Vol. 18 No. 3/2014, INFOREC Publishing House, DOI: 10.12948/issn14531305/18.3.2014.08, ISSN: 1453-1305, EISSN: 1842-8088, p. 91-102, available online http://www.revistaie.ase.ro/content/71/08 \%20-\%20Zamfir.pdf

[16] J. Scotland - Exploring the Philosophical Underpinnings of Research: Relating Ontology and Epistemology to the Methodology and Methods of the Scientific, Interpretive, and Critical Research Paradigms, English Language Teaching; Vol. 5, No. 9; 2012, ISSN 1916-4742 E-ISSN 1916-4750, Published by Canadian Center of Science and Education, http://www.ccsenet.org/journal/index.php /elt

[17] Wil van der Aalst, C. Stahl - Modeling Business Processes: A Petri Net-Oriented 
Approach, (Cooperative Information Systems), Publisher: The MIT Press (May 27, 2011) ISBN: 978-0262015387

[18] G. Zamfir- Theoretical and Factual Meaning in Assisted Instruction, Informatica Economică, Vol. 15 No. 2/2011, ISSN: $\quad 1453-1305, \quad$ p. 94-106, http://revistaie.ase.ro/content/58/09\%20-
\%20Zamfir.pdf

[19] G. Zamfir - Concepts Map Approach in e-Classroom, Informatica Economică, Vol. 16, no. 3, 2012, ISSN 1453-1305, EISSN 1842-8088, Available online: http://www.revistaie.ase.ro/content/63/11 $\% 20-\% 20 Z$ Zamfir.pdf

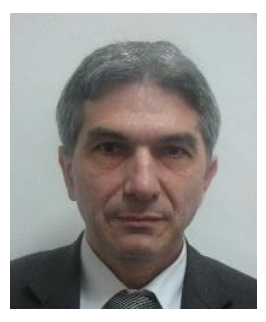

Gabriel ZAMFIR has graduated the Faculty of Planning and Economic Cybernetics in 1984 when he was distributed as analyst in the Research Institute for Computer Technique. In 1993, he joined the staff of the Bucharest University of Economics. In 2000, he finalized the doctoral thesis Computer Assisted Instruction in Economics. Currently he is full Professor of Computer Assisted Instruction within the Department for Training the Teachers, involved in designing education for metacognitive disciplines. 